Başhan, Veysi

Demirel, Hakan

Gul, Muhammet

http://dx.doi.org/10.21278/brod71203

ISSN 0007-215X

eISSN 1845-5859

\title{
A NOVEL RISK EVALUATION APPROACH FOR FREQUENTLY ENCOUNTERED RISKS IN SHIP ENGINE ROOMS
}

UDC 629.5.026.2

Original scientific paper

\begin{abstract}
Summary
The purpose of this study is to evaluate risks which are frequently encountered in the engine room on-board. In this context, twenty common risks are assessed using the neutrosophic analytic hierarchy process (N-AHP) and trapezoidal fuzzy technique for order preference by similarity to ideal solution (TrF-TOPSIS). In maritime risk evaluation, since it is frequently required the linguistic assessment of decision-makers to achieve a robust risk assessment tool, neutrosophic sets and fuzzy sets are used together in this study. Neutrosophic sets represent real-world problems effectively by considering all aspects of decision-making situations, (i.e. truthiness, indeterminacy, and falsity). Therefore, AHP is integrated with neutrosophic sets to assign weights of risk parameters initially. Then, the encountered risks are prioritized by TrF-TOPSIS. Finally, preventative actions for the risks have been discussed. In conclusion of the study, it is shown that skin exposure to the fuels/oils, exposure to chemicals and exposure to high pressure and temperature liquids are the most important risks through the engine room on-board. This study both emphasizes the importance of preventing damage to crew in the risk assessment of ship engine rooms and aims to increase the level of safety control and minimize the potential environmental impacts of a ship's damage.
\end{abstract}

Key words: $\quad$ maritime risk evaluation; ship engine room; neutrosophic sets; AHP; fuzzy TOPSIS

\section{Introduction}

Mostly, there is a great meaning relation among some concepts. Complexity may arise when using these terms. For example, concepts such as incident, accident, safety, hazard, risk, and consequence can create confusion in minds. Basically, incident can be defined as workrelated events in which a personnel injury, damage to the environment, loss of property (regardless of severity) or fatality occurred. Accident is an unintended event involving fatality, injury or damage. Hazard is source, situation or acts with a potential for harm in terms of human injury. Furthermore, risk is defined as a situation involving exposure to any kind of danger or expose someone or something valued to danger, harm or loss. In this context, International Maritime Organization (IMO) -known as a mandatory rule-maker in maritime sector- describes 
Formal Safety Assessment (FSA) as "a rational and systematic process for assessing the risks associated with shipping activity and for evaluating the costs and benefits of IMO's options for reducing these risks" [1]. However, Montewka et al. [2] indicate that there is an impression that the definition of risk does not fully reflect the way the risk is explained and that the components related to the definition of risk can change depending on the content. In this regard, Slovic [3] carried out comprehensive and pioneering work on risk perception research. He studied the people's judgments when they are asked to characterize and assess hazardous activities and technologies. In the literature, there are studies on risks in many different areas [4]-[6]. It can be seen that risk studies have been carried out mostly on land-based facilities or technologies. As in most of the terrestrial industrial facilities, the working environments in the ships have also many different risks and because a limited number of studies have been conducted in terms of ship and the maritime sector it needs to be examined in detail. As it is known, when public ship accidents occur resulting in extraordinary pollution in the seas, public conscience activates and encourages politicians to take more comprehensive measures. Taking this into consideration, Trbojevic and Carr [7] examined safety improvements in port with risk-based methodology. First, they carried out hazard identification and qualitative risk assessment to establish hazard barriers that must or should be present to prevent disclosure of hazards. Then, the controls for the management of these hazards are developed and integrated into the Safety Management System (SMS). Wang [8] applied a subjective modelling tool to formal ship safety assessment (SSA) by using fuzzy sets. Huntington et al. [9] carried out a study on ships and rules by considering several risks like ship strikes of whales, noise disturbance, pollution and oil spill in terms of ship traffic through Bering Strait. Hu et al. [10] examined numerical risk assessment and generic risk model in FSA, and also frequency and severity criteria in ship navigation are discussed. They presented a new model based on relative risk assessment (MRRA). Their models offer a risk-assessment approach based on fuzzy functions and take detailed information about the accident characteristics into account. Zhang et al. [11] applied Fuzzy Rule-Based Evidential Reasoning (FRBER) to an Inland Waterway Transportation System (IWTS) based on a hierarchical model for navigation risk. They have proven and confirmed the proposed method by analyzing the navigation risks of three different regions of the Yangtze River which is the longest river in Asia and the third-longest river in the world after the Amazon. They stated that their approach could be applied to model IWTS behaviours in other areas, such as America and Europe, to improve the safety of inland waterways. Mentes et al. [12] studied the FSA based approach combined with fuzzy set theory (FST), ordered weighted geometric averaging operator (OWGA) and decision making trial and evaluation laboratory technique (DEMATEL) for risk assessment of cargo ships at coasts and open seas of Turkey. Fu et al. [13] underlined the importance of the advantages of short sea routes which have recently forced ships to travel in such routes that are unfortunately challenging environments like Arctic waters. They indicated that in order to ensure safe operation in these areas, the potential risks of ship accidents should be systematically analyzed, evaluated and managed with the relevant uncertainties. In their study, the quantitative approach carried out in a four-stage study, including an event tree model, accident scenario modelling, probabilistic and dependency analysis of the associated intermediate events, and risk assessment for the resulting results. Akyildiz and Mentes [14] presented a risk assessment model for risk management and decision making. Through their analysis, the four main aspects of the uncertainty proposed by the authors: the level of understanding, the quality of information, the level of uncertainty of cargo ship accidents and the sensitivity levels of the model parameters, are integrated into the model parameters to analyze cargo ship accidents. Furthermore, Chauvin et al. [15] investigated collisions at sea by using Human Factor Analysis and Classification System (HFACS). In their results, it is indicated that unsafe acts are divided into two categories: decision and perception. Briefly, the authors stated that in open seas, the master's decisions 
should be investigated in case of incompatible with SMS. Kececi and Arslan [16] performed a Ship Accident Root Cause Evaluation (SHARE) analysis on a real ship accident case by the fuzzy Strengths, Weaknesses, Opportunities and Threats (SWOT) Analytic Hierarchy Process (AHP) method to demonstrate the causes of marine accidents and to implement appropriate corrective actions. Eliopoulou et al. [17] studied on a statistical analysis of ship accidents and showed that, although the frequency of ship accidents has increased in general over the last decade, the safety levels of various ship types have not changed significantly, because the results of the accidents remain at an average level. Akyuz and Celik [18] performed a study by using the Success Likelihood Index Method (SLIM) which is extended with fuzzy logic to understand the role of the human factor in maritime risk evaluation. They studied one of the specific operations of ships that is called Ballast Water Treatment (BWT). Consequently, they found that the riskiest phase is maintenance activities such as tank cleaning. Gul et al. [19] proposed a risk-based approach including the methods of Fine-Kinney method, FAHP, and fuzzy VIKOR. They applied it to ballast tank maintenance process in the maritime industry. Çakıroğlu et al. [20] performed a fuzzy AHP approach for choosing a suitable tugboat to be used at the port within the framework of design, operation and financial criteria. Demirel et al. [21] proposed a fuzzy AHP (Analytical Hierarchy Process) and ELECTRE (Elemination and Choice Translation Reality English) method to select the most effective roll stabilization system for a fishing vessel. Akdemir and Beskese [22] studied on a fuzzy AHP based decision model to provide practitioners with a decision support tool against further trade of a ship for the sale of demolition. Ding et al. [23] introduced an international shipping case and demonstrated that the proposed fuzzy MCDM model can be used to efficaciously select the best middle manager. KobylińSki [24] carried out a study on risks of ships which occur due to forces of the sea. When the above detailed literature is examined, it is clear that most of the studies give place to operational situations. However, the engine rooms on ships are like a large industrial factory. In engine rooms, there are many different machines that work on several different conditions and have many risky situations. Başhan and Demirel [25] evaluated the most common critical operational faults of marine diesel generator engines by using Decision Making Trial and Evaluation Laboratory (DEMATEL) method. Bashan and Ust [26] assessed super critical carbon dioxide Brayton power system which also can be used as a propulsion system of a ship by using fuzzy DEMATEL method. The diesel generator is one of the most important auxiliary engines in ships and it meets the power requirements of all auxiliary machinery on board, and most of its operations have many risks. Most of the ship machines operate at high temperature and pressure. Moreover, there are electric-electronic circuits in ship engine rooms and there are hazardous chemical risky liquids carried/used. Therefore, seafarers face many risks such as an explosion, fire, chemical exposure or inhalation of toxic/poison gaseous, etc.

Apart from prior studies, in this study twenty risks that are frequently encountered in the engine room are assessed by using N-AHP \& TrF-TOPSIS methods. In this study, triangular Neutrosophic sets and trapezoidal fuzzy sets are combined with AHP and TOPSIS multi-criteria decision methods, respectively. Neutrosophic sets are a generalization of classical, fuzzy and intuitionistic fuzzy sets. It reflects uncertain, inconsistent, and incomplete information about real-world problems. In neutrosophic sets, decision-makers consider truth-membership, indeterminacy membership and falsity-membership functions. By integrating this aspect of neutrosophic sets with AHP, the preference judgment values of the decision-makers are described efficiently. On the other hand, the TOPSIS method is applied to risk assessment problems many times in the literature [27]-[30]. Mahdevari et al. [31] investigated risk associated with health and safety of coal miners by using fuzzy TOPSIS methods. Yazdi [32] proposed a new intuitionistic fuzzy hybrid TOPSIS approach for risk matrix aiming to improve effectiveness and reliability of approach. Collan et al. [33] carried out a study by introducing new closeness coefficients for fuzzy TOPSIS and numerically performed to a research and 
development project selection issue. It has several pluses as follows [29]: It allows the experts to assign judgments to the hazards and associated risks by means of linguistic terms, which are better interpreted by humans, fuzzy in nature and then transferred into trapezoidal fuzzy numbers. In this study, TrF-TOPSIS is applied to analyze the risks frequently encountered in the engine room, since it has more capability in handling uncertainties, simultaneous consideration of the positive and the negative ideal points, simple computation and logical concept.

In the view of mentioned works, although a wide range of AHP and TOPSIS-based works have been performed to assess the risks, there is no practical approach using extended AHP with neutrosophic sets and TOPSIS with trapezoidal fuzzy sets applied to maritime risk evaluation. To remedy the gap, this paper aims at proposing a new risk evaluation approach for prioritizing risks in the maritime industry.

\section{Methodology}

In this section, the followed methodology is described in the lights of preliminaries of neutrosophic sets, the AHP based on neutrosophic sets named N-AHP, and trapezoidal fuzzy numbers-based TOPSIS techniques.

\subsection{Neutrosophic analytic hierarchy process (N-AHP)}

\subsubsection{Preliminaries on neutrosophic sets}

Neutrosophic set is a general version of classical, fuzzy and intuitionistic fuzzy sets [34]. They were first developed by Smaradache [35]. These sets reflect uncertainty, inconsistency and real-world problems better than classical fuzzy sets [34], [36], [37]. A single-valued triangular neutrosophic number is as follows: $\tilde{n}=\left\langle\left(n_{1}, n_{2}, n_{3}\right) ; \alpha_{\tilde{n}}, \beta_{\tilde{n}}, \theta_{\tilde{n}}\right\rangle$. Where $n_{1}, n_{2}, n_{3}$ are the lower, median and upper value of neutrosophic number and $\alpha_{\tilde{n}}, \beta_{\tilde{n}}, \theta_{\tilde{n}}$ are the truthmembership, indeterminacy-membership and falsity-membership functions, respectively. These functions are defined as follows:

The truth-membership function indicated as Eq. (1)

$$
T_{\tilde{n}}(x)=\left\{\begin{array}{cl}
\alpha_{\tilde{n}}\left(\frac{x-n_{1}}{n_{2}-n_{1}}\right) & \left(n_{1} \leq x \leq n_{2}\right) \\
\alpha_{\tilde{n}} & \left(x=n_{2}\right) \\
\alpha_{\tilde{n}}\left(\frac{n_{3}-x}{n_{3}-n_{2}}\right) & \left(n_{2} \leq x \leq n_{3}\right) \\
0 & \text { otherwise }
\end{array}\right.
$$

The indeterminacy-membership function as Eq. (2)

$$
I_{\tilde{n}}(x)=\left\{\begin{array}{cl}
\frac{\left(n_{2-} x+\beta_{\widetilde{n}}\left(x-n_{1}\right)\right)}{\left(n_{2}-n_{1}\right)} & \left(n_{1} \leq x \leq n_{2}\right) \\
\beta_{\tilde{n}} & \left(x=n_{2}\right) \\
\frac{\left(x-n_{2}+\beta_{\tilde{n}}\left(n_{3}-x\right)\right)}{\left(n_{3}-n_{2}\right)} & \left(n_{2} \leq x \leq n_{3}\right) \\
1 & \text { otherwise }
\end{array}\right.
$$

The falsity-membership function as indicated Eq. (3)

$$
F_{\tilde{n}}(x)=\left\{\begin{array}{cl}
\frac{\left(n_{2-} x+\theta_{\tilde{n}}\left(x-n_{1}\right)\right)}{\left(n_{2}-n_{1}\right)} & \left(n_{1} \leq x \leq n_{2}\right) \\
\theta_{\tilde{n}} & \left(x=n_{2}\right) \\
\frac{\left(x-n_{2}+\theta_{\tilde{n}}\left(n_{3}-x\right)\right)}{\left(n_{3}-n_{2}\right)} & \left(n_{2} \leq x \leq n_{3}\right) \\
1 & \text { otherwise }
\end{array}\right.
$$


Here, $\alpha_{\tilde{n}}, \beta_{\tilde{n}}, \theta_{\tilde{n}}$ demonstrate the maximum truth-membership degree, minimum indeterminacy-membership degree and minimum falsity-membership degree, respectively. Some mathematical operations related to the neutrosophic sets are defined as in the following:

Definition 1 [34], [36], [37]: Addition of two triangular neutrosophic numbers.

Let $\tilde{n}=\left\langle\left(n_{1}, n_{2}, n_{3}\right) ; \alpha_{\tilde{n}}, \beta_{\tilde{n}}, \theta_{\tilde{n}}\right\rangle$ and $\tilde{s}=\left\langle\left(s_{1}, s_{2}, s_{3}\right) ; \alpha_{\tilde{s}}, \beta_{\tilde{s}}, \theta_{\tilde{s}}\right\rangle$ be two single valued triangular neutrosophic numbers. Then addition of these two numbers can be computed as in Eq. (4):

$$
\tilde{n}+\tilde{s}=\left\langle\left(n_{1}+s_{1}, n_{2}+s_{2}, n_{3}+s_{3}\right) ; \alpha_{\tilde{n}} \wedge \alpha_{\tilde{s}}, \beta_{\tilde{n}} \bigvee \beta_{\tilde{s}}, \theta_{\tilde{n}} \bigvee \theta_{\tilde{s}}\right\rangle
$$

Definition 2 [34], [36], [37]: Subtraction of two triangular neutrosophic numbers. This can be computed as in Eq. (5):

$$
\tilde{n}-\tilde{s}=\left\langle\left(n_{1}-s_{3}, n_{2}-s_{2}, n_{3}-s_{1}\right) ; \alpha_{\tilde{n}} \wedge \alpha_{\tilde{s}}, \beta_{\tilde{n}} \bigvee \beta_{\tilde{s}}, \theta_{\tilde{n}} \vee \theta_{\tilde{s}}\right\rangle
$$

Definition 3 [34], [36], [37]: Inverse of a triangular neutrosophic number. Let $\tilde{n}=$ $\left\langle\left(n_{1}, n_{2}, n_{3}\right) ; \alpha_{\tilde{n}}, \beta_{\tilde{n}}, \theta_{\tilde{n}}\right\rangle$ be a single valued triangular neutrosophic number. Then inverse of this number can be computed as in Eq. (6):

$$
\tilde{n}^{-1}=\left\langle\left(\frac{1}{n_{3}}, \frac{1}{n_{2}}, \frac{1}{n_{1}}\right) ; \alpha_{\tilde{n}}, \beta_{\tilde{n}}, \theta_{\tilde{n}}\right\rangle \text { where } \tilde{n} \neq 0
$$

Definition 4 [34], [36], [37]: Division of two triangular neutrosophic numbers

Let $\tilde{n}=\left\langle\left(n_{1}, n_{2}, n_{3}\right) ; \alpha_{\tilde{n}}, \beta_{\tilde{n}}, \theta_{\tilde{n}}\right\rangle$ and $\tilde{s}=\left\langle\left(s_{1}, s_{2}, s_{3}\right) ; \alpha_{\tilde{s}}, \beta_{\tilde{s}}, \theta_{\tilde{s}}\right\rangle$ be two single valued triangular neutrosophic numbers. Then division of these two numbers can be computed as in Eq. (7):

$$
\tilde{n} / \tilde{s}= \begin{cases}\left\langle\left(\frac{n_{1}}{s_{3}}, \frac{n_{2}}{s_{2}}, \frac{n_{3}}{s_{1}}\right) ; \alpha_{\tilde{n}} \wedge \alpha_{\tilde{s}}, \beta_{\tilde{n}} \vee \beta_{\tilde{s}}, \theta_{\tilde{n}} \vee \theta_{\tilde{s}}\right\rangle & \text { if } n_{3}>0, s_{3}>0 \\ \left\langle\left(\frac{n_{3}}{s_{3}}, \frac{n_{2}}{s_{2}}, \frac{n_{1}}{s_{1}}\right) ; \alpha_{\tilde{n}} \wedge \alpha_{\tilde{s}}, \beta_{\tilde{n}} \vee \beta_{\tilde{s}}, \theta_{\tilde{n}} \vee \theta_{\tilde{s}}\right\rangle & \text { if } n_{3}<0, s_{3}>0 \\ \left\langle\left(\frac{n_{3}}{s_{1}}, \frac{n_{2}}{s_{2}}, \frac{n_{1}}{s_{3}}\right) ; \alpha_{\tilde{n}} \wedge \alpha_{\tilde{s}}, \beta_{\tilde{n}} \vee \beta_{\tilde{s}}, \theta_{\tilde{n}} \vee \theta_{\tilde{s}}\right\rangle & \text { if } n_{3}<0, s_{3}<0\end{cases}
$$

Definition 5 [34], [36], [37]: Multiplication of two triangular neutrosophic numbers

Let $\tilde{n}=\left\langle\left(n_{1}, n_{2}, n_{3}\right) ; \alpha_{\tilde{n}}, \beta_{\tilde{n}}, \theta_{\tilde{n}}\right\rangle$ and $\tilde{s}=\left\langle\left(s_{1}, s_{2}, s_{3}\right) ; \alpha_{\tilde{s}}, \beta_{\tilde{s}}, \theta_{\tilde{s}}\right\rangle$ be two single valued triangular neutrosophic numbers. Then multiplication of these two numbers can be computed as in Eq. (8):

$$
\tilde{n} * \tilde{s}=\left\{\begin{array}{l}
\left\langle\left(n_{1} * s_{1}, n_{2} * s_{2}, n_{3} * s_{3}\right) ; \alpha_{\tilde{n}} \wedge \alpha_{\tilde{s}}, \beta_{\tilde{n}} \bigvee \beta_{\tilde{s}}, \theta_{\tilde{n}} \bigvee \theta_{\tilde{s}}\right\rangle \text { if } n_{3}>0, s_{3}>0 \\
\left\langle\left(n_{1} * s_{3}, n_{2} * s_{2}, n_{3} * s_{1}\right) ; \alpha_{\tilde{n}} \wedge \alpha_{\tilde{s}}, \beta_{\tilde{n}} \bigvee \beta_{\tilde{s}}, \theta_{\tilde{n}} \bigvee \theta_{\tilde{s}}\right\rangle \text { if } n_{3}<0, s_{3}>0 \\
\left\langle\left(n_{3} * s_{3}, n_{2} * s_{2}, n_{1} * s_{1}\right) ; \alpha_{\tilde{n}} \wedge \alpha_{\tilde{s}}, \beta_{\tilde{n}} \bigvee \beta_{\tilde{s}}, \theta_{\tilde{n}} \bigvee \theta_{\tilde{s}}\right\rangle \text { if } n_{3}<0, s_{3}<0
\end{array}\right.
$$

\subsubsection{Steps of N-AHP}

The AHP method originally was proposed by Saaty [38]. Later, Saaty [39] wrote several books about the AHP method and proposed the Analytic Network Process (ANP) method [40], [41]. Saaty's AHP and ANP was integrated with fuzzy sets and its extensions such as fuzzy extent analysis [42], neutrosophic sets [35], interval type-2 fuzzy sets [43], hesitant fuzzy sets [44], intuitionistic fuzzy sets [45] and Pythagorean fuzzy sets [27], [30], [46]-[48]. As in the classical AHP method, N-AHP has the following main steps: decomposition, pair-wise comparison, and synthesis of priorities. The detailed procedural flow of N-AHP is provided with details below in five steps.

Step 1: This step is about problem conceptualization in terms of hierarchical manner. It means that the problem is dealt with goals, alternatives, criteria, and sub-criteria. 
Step 2: This step is related to the construction of pairwise comparison matrix, in other words, the neutrosophic decision matrix. The vagueness of decision-makers is characterized by triangular neutrosophic numbers $\tilde{n}_{i j}$. This matrix is shown in Eq. (9) below:

$$
\tilde{n}=\left[\begin{array}{ccc}
1 & \cdots & \tilde{n}_{1 m} \\
\vdots & \ddots & \vdots \\
\tilde{n}_{m 1} & \cdots & 1
\end{array}\right] \text { where } \tilde{n}_{j i}=\tilde{n}_{i j}^{-1} .
$$

Step 3 [34], [36], [37]: This step is regarding determination of the weight of each criterion from corresponding neutrosophic decision matrix. To do this, neutrosophic decision matrix is initially transformed to deterministic decision matrix, using the Eqs. (10-11). Let $\tilde{n}=$ $\left\langle\left(n_{1}, n_{2}, n_{3}\right) ; \alpha_{\tilde{n}}, \beta_{\tilde{n}}, \theta_{\tilde{n}}\right\rangle$ be a single valued triangular neutrosophic number, then,

$$
\begin{aligned}
& S\left(\tilde{n}_{i j}\right)=\frac{1}{16}\left[n_{1}+n_{2}+n_{3}\right] x\left(2+\alpha_{\tilde{n}}-\beta_{\tilde{n}}-\theta_{\tilde{n}}\right) \\
& A\left(\tilde{n}_{i j}\right)=\frac{1}{16}\left[n_{1}+n_{2}+n_{3}\right] x\left(2+\alpha_{\tilde{n}}-\beta_{\tilde{n}}-\theta_{\tilde{n}}\right)
\end{aligned}
$$

These two terms are score and accuracy degrees of $\tilde{n}_{i j}$, respectively. After this transformation, the matrix is turned into a deterministic decision matrix. Using the deterministic decision matric, the eigen vector calculation can be performed. From this step, the calculations are the same as the calculations in the classical AHP method.

Step 4: In this step, the consistency ratio (CR) is calculated. If the obtained CR value is lower than 0.1 , it can be said that the evaluation of expert's judgment is consistent. The steps of CR computation are as follows:

Step 4.1: Multiply the pairwise comparison matrix by the relative priorities

Step 4.2: Divide the weighted sum vector elements by the associated priority value

Step 4.3: Compute the average (denoted $\lambda_{\max }$ ) of the values from Step 4.2

Step 4.4: Compute the consistency index $(\mathrm{CI})\left(C I=\frac{\lambda_{\max }-n}{n-1}\right)$, where $n$ is the number of items being compared.

Step 4.5: Compute the consistency ratio $\mathrm{CR}=\mathrm{CI} / \mathrm{RI}$, where $\mathrm{RI}$ is the random index (CI of the randomly generated pairwise comparison matrix) as shown in [49], [50].

Step 5: In the last step, overall priority of each criterion is calculated, and final rankings are determined.

2.2 Trapezoidal fuzzy numbers-based technique for order preference by similarity to ideal solution (TrF-TOPSIS)

\subsubsection{Trapezoidal fuzzy numbers and related linguistic terms}

The TOPSIS method was firstly proposed by Hwang and Yoon [51]. It is based on the compromise solution concept which selects the solution with the shortest distance from the ideal solution, and the farthest distance from the negative ideal solution. In the literature, TOPSIS is extended by using various versions of fuzzy numbers [49], [52]. A single-valued trapezoidal fuzzy number $A$ is demonstrated with its membership function as follows in Eqs (12-13):

$$
\tilde{A}=\left(a_{1}, a_{2}, a_{3}, a_{4}\right), a_{1} \leq a_{2} \leq a_{3} \leq a_{4}
$$




$$
\mu_{\tilde{A}}(x)=\left\{\begin{array}{rc}
0, & \left.x<a_{1}\right) \\
\left(\frac{x-a_{1}}{a_{2}-a_{1}}\right), & \left(a_{1} \leq x \leq a_{2}\right) \\
\left(\frac{a_{3}-x}{a_{3}-a_{2}}\right), & \left(a_{2} \leq x \leq a_{3}\right) \\
1, & x>a_{3}
\end{array}\right.
$$

Mathematical operations of two trapezoidal fuzzy numbers can be found at Cheng and Lin [53]. For the current study, linguistic variables and corresponding fuzzy numbers in trapezoidal format in the study of Samantra [54] are utilized. The seven-point scale is represented as in Table 1 below.

Table 1 Seven-point fuzzy linguistic scale [54].

\begin{tabular}{ll}
\hline Linguistic term & Fuzzy number \\
\hline Absolutely certain (AC) & $(0.8,0.9,1,1)$ \\
Very frequent (VF) & $(0.7,0.8,0.8,0.9)$ \\
Frequent (F) & $(0.5,0.6,0.7,0.8)$ \\
Probable (P) & $(0.4,0.5,0.5,0.6)$ \\
Occasional (O) & $(0.2,0.3,0.4,0.5)$ \\
Rare (R) & $(0.1,0.2,0.2,0.3)$ \\
Very rare (VR) & $(0,0,0.1,0.2)$ \\
\hline
\end{tabular}

\subsubsection{Steps of TrF-TOPSIS}

The procedure used in Chen's [55] TrF-TOPSIS method was followed for the hazard prioritization aim in the case study presented in this paper. The steps are as follows [29], [49], [56], [57]:

Step 1: The scores of alternatives with respect to each criterion are obtained considering a decision-making group with K experts by this formula: $\tilde{x}_{i j}=\frac{1}{K}\left[\tilde{x}_{i j}^{1}(+) \tilde{x}_{i j}^{1}(+) \ldots .(+) \tilde{x}_{i j}^{K}\right]$. While $A=\left\{A_{i} \mid i=1, \ldots, m\right\}$ shows the set of alternatives, $C=\left\{C_{j} \mid j=1, \ldots, n\right\}$ represents the criteria set. $X=\left\{X_{i j} \mid i=1, \ldots, m ; j=1, \ldots, n\right\}$ denotes the set of fuzzy ratings, and $\widetilde{w}=\left\{\widetilde{w}_{j} \mid j=1, \ldots ., n\right\}$ is the set of fuzzy weights. The linguistic variables are described by trapezoidal fuzzy number as follows: $\tilde{x}_{i j}=\left(a_{i j}, b_{i j}, c_{i j}, d_{i j}\right)$.

Step 2: Normalized ratings are determined by Eq. (14).

$$
\tilde{r}_{i j}=\left\{\begin{array}{l}
\left(\frac{a_{i j}}{d_{j}^{*}}, \frac{b_{i j}}{d_{j}^{*}}, \frac{c_{i j}}{d_{j}^{*}}, \frac{d_{i j}}{d_{j}^{*}}\right), \text { where } d_{j}^{*}=\max _{i} d_{i j} \text { if } j \in \text { benefit criteria } \\
\left(\frac{a_{j}^{-}}{d_{i j}}, \frac{a_{j}^{-}}{c_{i j}}, \frac{a_{j}^{-}}{b_{i j}}, \frac{a_{j}^{-}}{a_{i j}}\right), \text { where } a_{j}^{-}=\min _{i} a_{i j} \text { if } j \in \cos \mathrm{t} \text { criteria }
\end{array}\right.
$$

Step 3: Weighted normalized ratings are obtained by Eq. (12).

$$
\tilde{v}_{i j}=w_{j}(x) \tilde{r}_{i j}, \quad i=1, \ldots ., m ; j=1, \ldots ., n
$$

Step 4: The fuzzy positive ideal point (FPIS,A*) and the fuzzy negative ideal point (FNIS, $\mathrm{A}^{-}$) are derived as in Eq. (16-17). Where $\mathrm{J}_{1}$ and $\mathrm{J}_{2}$ are the benefit and the cost attributes, respectively. 


$$
\begin{aligned}
& \text { FPIS }=A^{*}=\left\{\tilde{v}_{1}^{*}, \tilde{v}_{2}^{*}, \ldots, \tilde{v}_{n}^{*}\right\} \text { where } \tilde{v}_{j}^{*}=(1,1,1,1) \\
& \text { FNIS }=\mathrm{A}^{-}=\left\{\tilde{v}_{1}^{-}, \tilde{v}_{2}^{-}, \ldots, \tilde{v}_{n}^{-}\right\} \text {where } \tilde{v}_{j}^{-}=(0,0,0,0)
\end{aligned}
$$

Step 5: The next step is about calculating the separation between the FPIS and the FNIS among the alternatives. The separation values can also be obtained by means of the vertex method as in Eq. (18-19):

$$
\begin{aligned}
& \tilde{\mathrm{S}}_{\mathrm{i}}^{*}=\sqrt{\frac{1}{4} \sum_{\mathrm{j}=1}^{\mathrm{n}}\left[\tilde{\mathrm{v}}_{\mathrm{ij}}-\tilde{\mathrm{v}}_{\mathrm{j}}^{*}\right]^{2}}, \quad \mathrm{i}=1, \ldots ., \mathrm{m} \\
& \tilde{\mathrm{S}}_{\mathrm{i}}^{-}=\sqrt{\frac{1}{4} \sum_{\mathrm{j}=1}^{\mathrm{n}}\left[\tilde{\mathrm{v}}_{\mathrm{ij}}-\tilde{\mathrm{v}}_{\mathrm{j}}^{-}\right]^{2}}, \quad \mathrm{i}=1, \ldots ., \mathrm{m}
\end{aligned}
$$

Step 6: Then, the defuzzified separation values are derived using the CoA (center of area) defuzzification method to calculate the similarities to the ideal solution. Next, the similarities to the ideal solution are given as Eq. (20).

$$
\mathrm{C}_{\mathrm{i}}^{*}=\tilde{\mathrm{S}}_{\mathrm{j}}^{-} /\left(\tilde{\mathrm{S}}_{\mathrm{j}}^{*}+\tilde{\mathrm{S}}_{\mathrm{j}}^{-}\right), \quad \mathrm{i}=1, \ldots ., \mathrm{m}
$$

The preferred orders are ranked according to $C_{i}^{*}$ in descending order to select the best final alternatives. Thus, referring to the proposed analysis, and according to the obtained $C_{i}^{*}$ values, the ranking order of all hazards can be determined.

\subsection{The overall picture of proposed methodology}

In this section, the proposed methodology is presented to prioritize hazards and analyze associated risks by N-AHP and TrF-TOPSIS methods. Figure 1 shows flow chart of the proposed methodology. Initially, problem description and risk identification are performed by meetings and snowball method. Then, in the second phase, experts assign weights of risk parameters by using N-AHP method. The risk parameters are as follows: severity, probability, sensitivity to personal protective equipment non-utilization (SPPENU), and undetectability. Finally, maritime risks related to the machinery are prioritized by using TrF-TOPSIS method. 


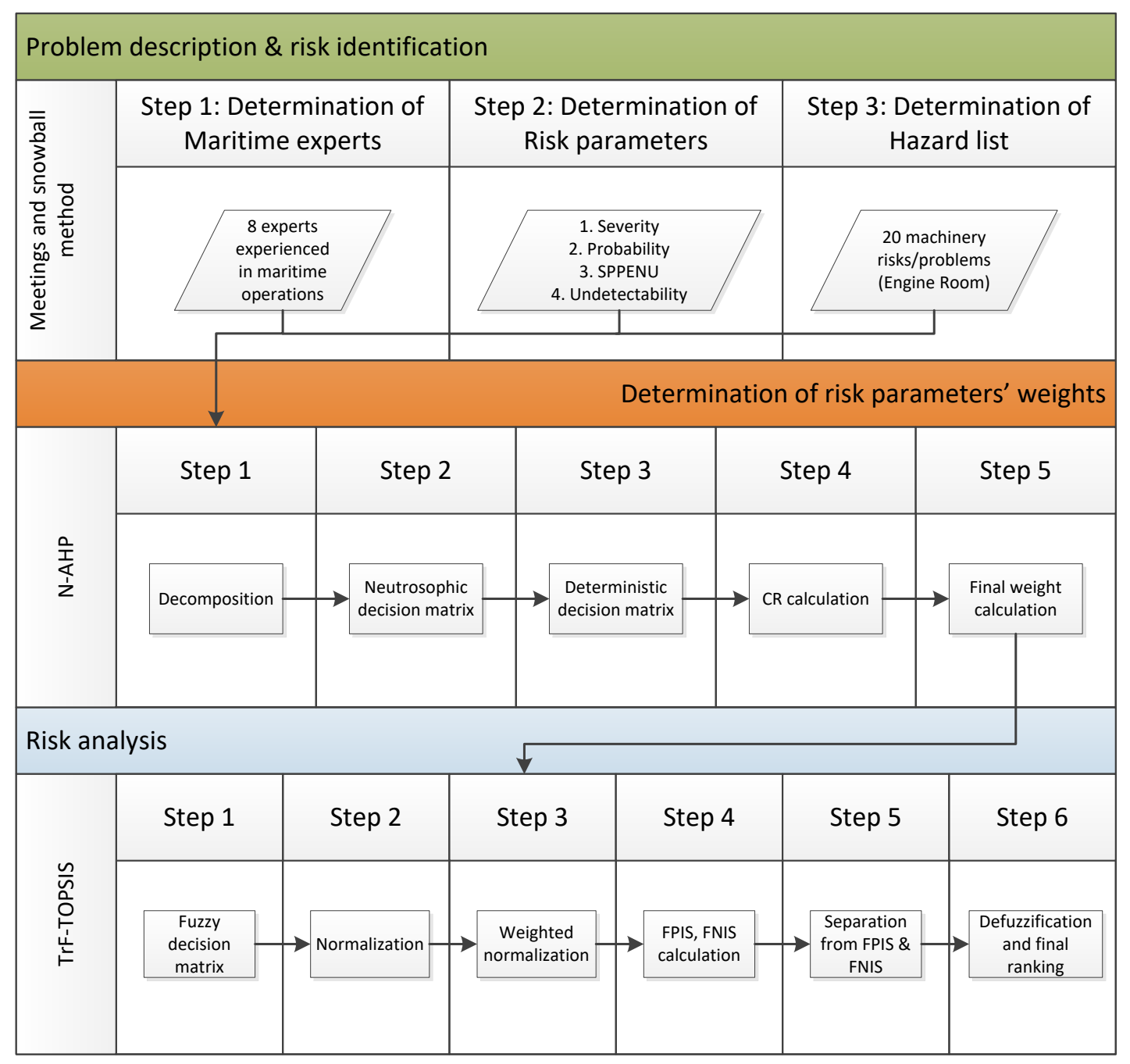

Fig. 1 Systematic procedural steps of the proposed methodology

\section{Case study: Evaluation of risks in ship engine room}

\subsection{Problem description and risk identification}

Regarding the first step of the application of the proposed methodology, determination of maritime experts who filled the questionnaires, determination of risk parameters and determination of hazard list were performed. Table 2 shows the detailed information about the expert group and their corresponding working experience. For reasons of anonymity, the identity of the experts is not revealed in this study. In the current study, eight experts participated in rating and analyzing occupational hazard risks. All members have experience in maritime industry with different levels. Since, the DPA and the two Machinery Superintendents have the highest experience level, they take participate the first phase of the approach (N-AHP implementation to determine importance levels of four risk parameters). Compared to the TrFTOPSIS phase, N-AHP phase requires a strategic assessment viewpoint rather than an operational assessment viewpoint. In the second phase of the approach, all the eight experts take participation in evaluating occupational hazard risks. We have assumed equal importance degree to the experts in both phases. In the literature, there exits some novel methods for expertise coefficient determination [58], [59].

Secondly, four risk parameters were considered within the scope of this study. Certainly, according to the ISO definition, risk is defined as combination of severity and probability. 
However, we believe that other two parameters named as SPPENU and undetectability represent the most important aspects of human behavior and working environment interaction in an industrial field. They are described as follows: (1) Severity addresses the evaluation of the severity of the more consistent injury that can be caused by an accident during the execution of hazardous activity. (2) Probability considers the combination of the occurrence probability of the accident and the probability that injuries to operators occur. (3) SPPENU considers the potential negative effect on the operator's health resulting from a failure to wear personal protective equipment (PPE) together with the expectation that the operator may not wear it. Sensitivity to PPE non-utilization considers the potential negative effect on the operator's health resulting from a failure to wear PPE together with the expectation that the operator may not wear it. (4) Undetectability is related to the interaction between the operator and the working environment such as machines and equipment.

The experts identified twenty hazards frequently encountered risks in ship engine rooms. The detailed information about the hazard list is provided in Table 3.

Table 2 Expert profile details

Expert Title and Years of experience in maritime

Expert-1 DPA (Designated Person Ashore) -CE (Chief Engineer) - MSc - Technical Manager of Shipping Company -32 years' experience

Expert-2 Machinery Superintendent -CE (Chief Engineer) - MSc - 25 years' experience

Expert-3 Machinery Superintendent -CE (Chief Engineer) -19 years' experience

Expert-4 CE (Chief Engineer) - Oceangoing watch keeping engineer -Ph.D- 18 years' experience

Expert-5 CE (Chief Engineer) - Oceangoing watch keeping engineer -MSc- 17 years' experience

Expert-6 $2^{\text {nd }}$ Engineer -Oceangoing watch keeping engineer -MSc- 17 years' experience

Expert-7 $2^{\text {nd }}$ Engineer -Oceangoing watch keeping engineer -MSc -15 years' experience

Expert-8 Naval Architecture and Marine Engineer -Shipyard -MSc- 15 years' experience

Table 3 Identified hazards

\begin{tabular}{ll}
\hline Hazard No. & Hazard and/or occurring of risk \\
\hline Hazard-1 & Falling from high spaces \\
Hazard-2 & Struck by falling objects \\
Hazard-3 & Personal injury \\
Hazard-4 & Oil spill \\
Hazard-5 & Skin exposure to fuels/oils \\
Hazard-6 & Pipe line burst due to excess pressure \\
Hazard-7 & Fire \\
Hazard-8 & Inhalation of poison/toxic gaseous \\
Hazard-9 & Electrocution \\
Hazard-10 & Exposure to high pressure and high temperature liquids \\
Hazard-11 & Lifting heavy objects \\
Hazard-12 & Excessive stress to ship structure
\end{tabular}




\begin{tabular}{ll} 
Hazard-13 & Exposure to chemicals \\
Hazard-14 & Interruption of power loss onboard \\
Hazard-15 & Explosion \\
Hazard-16 & Drop of crane or grab because of break off wire \\
Hazard-17 & Explosion on auxiliary machinery components \\
Hazard-18 & Loose floor plating \\
Hazard-19 & Engine room lightning damage \\
Hazard-20 & Involuntary explosion of carbon dioxide extinguishing system \\
\hline
\end{tabular}

\subsection{Determination of risk parameters' weights by N-AHP}

In this step, the neutrosophic pair-wise comparison matrix is initially constructed following the Step 2 of sub-section 2.1.2. In this step, lower, median and upper values of neutrosophic numbers and the truth- membership, indeterminacy membership and falsity-membership functions are adapted from Abdel-Basset et al. 's [34] study. The matrix is given in Table 4.

Table 4 The neutrosophic pair-wise comparison matrix

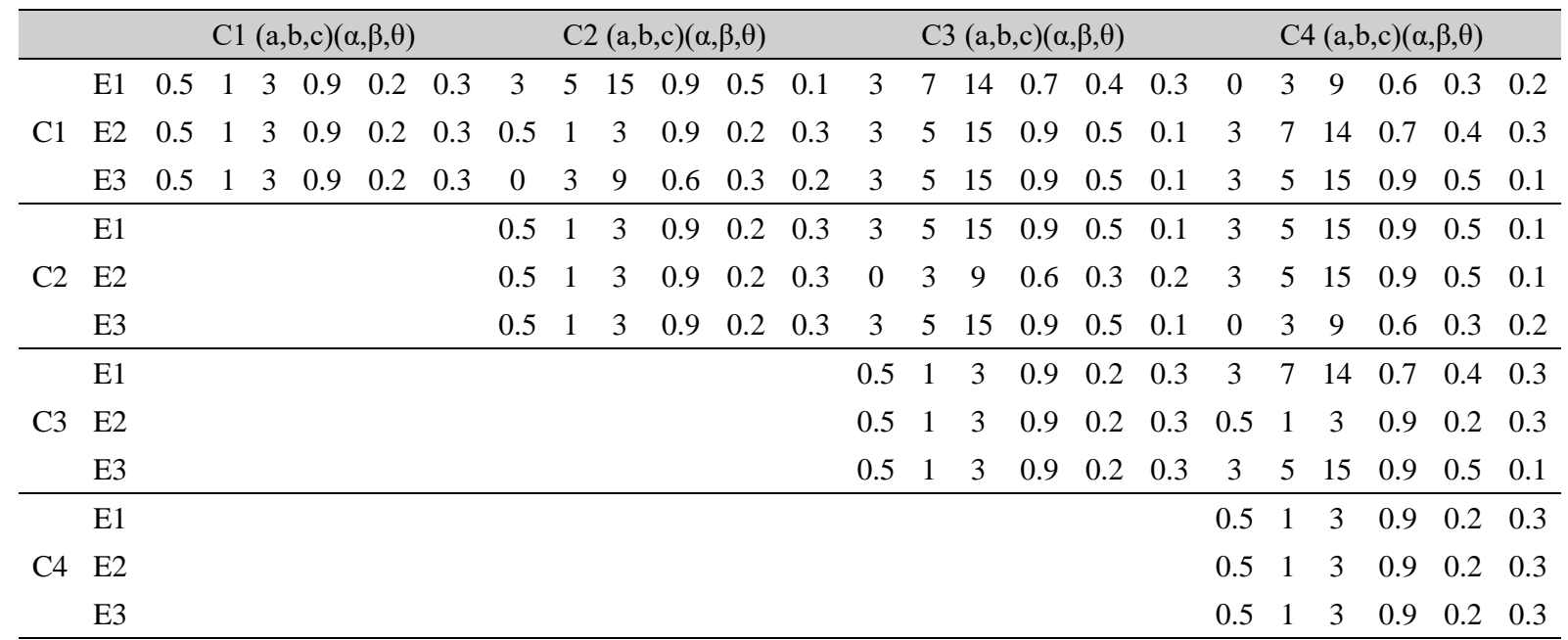

Note: C1: Severity; C2: Probability; C3: SPPENU; C4: Undetectability; (a,b,c) refers to the lower, median and upper of neutrosophic number; $(\alpha, \beta, \theta)$ refers to the truth- membership, indeterminacy membership and falsity-membership functions; E1: Expert-1; E2: Expert-2; E3: Expert-3.

By using Equations (7) and (8), the previous neutrosophic pair-wise comparison matrix transformed to deterministic pair-wise comparison matrix as in Table 5.

Table 5 The deterministic pair-wise comparison matrix

\begin{tabular}{ccccc}
\hline & $\mathrm{C} 1$ & $\mathrm{C} 2$ & $\mathrm{C} 3$ & $\mathrm{C} 4$ \\
\hline $\mathrm{C} 1$ & 0.675 & 1.852 & 3.204 & 2.627 \\
$\mathrm{C} 2$ & 0.806 & 0.675 & 2.729 & 2.729 \\
$\mathrm{C} 3$ & 0.313 & 0.413 & 0.675 & 2.327 \\
$\mathrm{C} 4$ & 0.424 & 0.413 & 0.706 & 0.675 \\
\hline
\end{tabular}

To ensure that all inputs of experts are consistent we made a CR test. From equations of Step 4 in sub-section 2.1.2, $\lambda_{\max }=$ average $\{1.688 / 0.402, \quad 1.306 / 0.316, \quad 0.650 / 0.159$, $0.496 / 0.123\}=4.115$ and $\mathrm{CI}=\left(\lambda_{\operatorname{maX}}-\mathrm{n}\right) / \mathrm{n}-1=(4.115-4) /(4-1)=0.038 . \mathrm{CR}=\mathrm{CI} / \mathrm{RI}=0.038 / 0.9=$ 0.042 . 
Using the eigenvector, the weights of four risk parameters are determined as in Figure 2. According to the results, the most important risk parameter is severity with a weight value of 0.402 . It is followed by probability, SPPENU and undetectability with the weight values of $0.316,0.159$ and 0.123 , respectively.

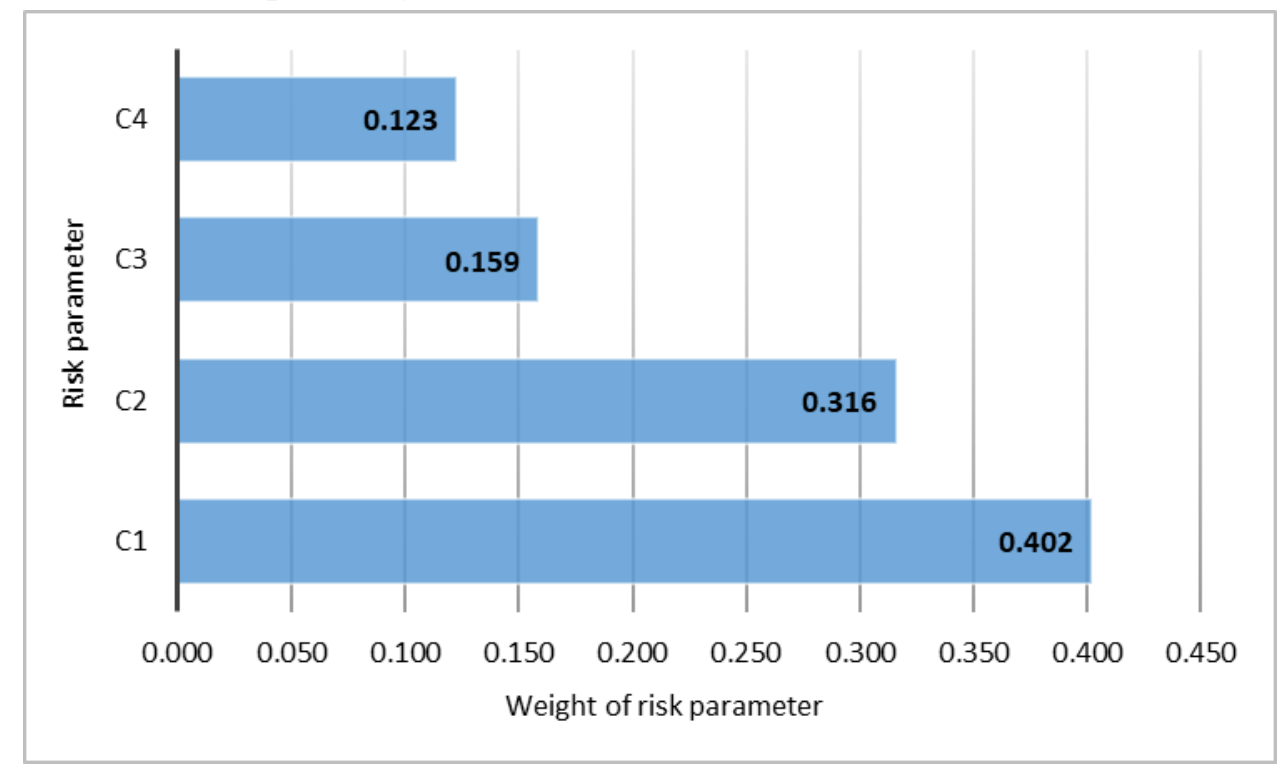

Fig. 2 Risk parameters' weights

\subsection{Risk analysis and prioritization by TrF-TOPSIS}

The last step of the proposed methodology is about risk analysis and prioritization by $\mathrm{TrF}$ TOPSIS. Utilizing the risk parameters' weights from N-AHP step, and the fuzzy evaluations of hazards with respect to four risk parameter, TrF-TOPSIS is applied. In the study, all eight maritime experts the maritime experts make the evaluation of twenty hazards using linguistic variables as shown in Table 1. The fuzzy linguistic variables in Table 1 is then transformed into fuzzy trapezoidal numbers as shown in Table 6. This is the first stage of the TrF-TOPSIS analysis.

Table 6 Trapezoidal fuzzy decision matrix in TrF-TOPSIS step

\begin{tabular}{|c|c|c|c|c|c|c|c|c|c|c|c|c|c|c|c|c|}
\hline \multirow{2}{*}{$\begin{array}{r}\text { Hazard } \\
\text { Hazard-1 }\end{array}$} & \multicolumn{4}{|c|}{4} & \multicolumn{4}{|c|}{-} & \multicolumn{4}{|c|}{ 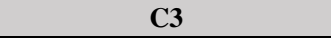 } & \multicolumn{4}{|c|}{ ( } \\
\hline & & 25 & & & & & & & & & & & & & & \\
\hline Hazal & & & & & & & & & & & & & & & & \\
\hline & & & & & & & & & & & & & & & & \\
\hline & & & & & & & & & & & & & & & & \\
\hline & & 38 & & & & & & & & & & & & 25 & & \\
\hline & & & & & & & & & & & & & & & & \\
\hline & & & & & & & & & & & & & & & & \\
\hline & & 50 & & & & & & & & & & & & & & \\
\hline & & & & & & & & & & & & & & & & \\
\hline & & 725 & & & & & & & & & & & & 00 & & \\
\hline & & 38 & & & & & & & & & & & & & & \\
\hline & & & & & & & & & & & & & & & & \\
\hline & & 75 & & & 8 & & 0.488 & 8 & & & 3 & & & 88 & & \\
\hline & & & & & & & & & & & & & & & & \\
\hline & & & & & & & & & & & & & & 38 & & \\
\hline & & & & & & & & & & & & & & & & \\
\hline & & & & & & & & & & & & & & 188 & & \\
\hline & & & & & & & & & & & & & & 50 & & \\
\hline & 413 & 513 & 0.5 & & 0.238 & & 0.413 & & & & 13 & & & 238 & 275 & 375 \\
\hline Hazard-20 & 650 & 750 & 0.775 & 0.863 & 0.088 & 0.138 & 0.188 & 0.288 & 0.238 & 0.325 & 0.375 & 0.475 & 0.188 & 0.263 & 0.325 & 0.413 \\
\hline
\end{tabular}


Then these values are normalized using Eq. (14) in step 2 of Section 2.2.2. Table 7 provides the normalized fuzzy decision matrix.

Table 7 Normalized fuzzy decision matrix in TrF-TOPSIS step

\begin{tabular}{|c|c|c|c|c|c|c|c|c|c|c|c|c|c|c|c|c|}
\hline \multirow{2}{*}{$\begin{array}{r}\text { Hazard } \\
\text { Hazard-1 }\end{array}$} & \multicolumn{4}{|c|}{4} & \multicolumn{4}{|c|}{42} & \multicolumn{4}{|c|}{$\mathrm{cJ}$} & \multicolumn{4}{|c|}{ 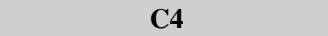 } \\
\hline & & 46 & & & & & & & & & & & & & & \\
\hline 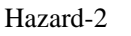 & & & & & & & & & & & & & & & & \\
\hline & & & & & & & & & & & & & & & & \\
\hline & & & & & & & & & & & & & & & & \\
\hline & & & & & & & & & & & & & & & & \\
\hline & & & & & & & & & & & & & & & & \\
\hline & & & & & & & & & & & & & & & & \\
\hline & & & & & & & & & & & & & & & & \\
\hline & & & & & & & & & & & & & & & & \\
\hline & & 4 & & & & & & & & & & & & & & \\
\hline & & & & & & & & & & & & & & & & \\
\hline & & & & & & & & & & & & & & & & \\
\hline & & 795 & 6 & 923 & 466 & & 672 & & & & & & 14 & 84 & & \\
\hline & & & & & & & & & & & & & & & & \\
\hline & & 6 & & & & & & & & & & & & 33 & & \\
\hline & & 897 & 74 & & 0.207 & & 70 & & & & & & & .579 & & \\
\hline & & & & & & & & & & & & & & & & \\
\hline & & 590 & & & 0.4 & & & & & & & & & & & \\
\hline & 423 & 526 & $0.5^{\circ}$ & & 8 & & 0.569 & & & & & & 0.246 & 333 & 86 & 0.526 \\
\hline Hazard-20 & 667 & 769 & 795 & 885 & 0.121 & 0.190 & 0.259 & 0.397 & 302 & 0.413 & 0.476 & 0.603 & 0.263 & 0.368 & 0.456 & 0.579 \\
\hline
\end{tabular}

The fuzzy risk parameter weights are added into the calculation in FTOPSIS analysis. The next step is to generate the weighted fuzzy decision matrix using. Using Eq. (15) fuzzy weighted decision matrix is obtained as in Table 8.

Table 8 Weighted normalized fuzzy decision matrix in TrF-TOPSIS step

\begin{tabular}{|c|c|c|c|c|c|c|c|c|c|c|c|c|c|c|c|c|}
\hline \multirow{2}{*}{$\begin{array}{r}\text { Hazard } \\
\text { Hazard-1 }\end{array}$} & \multicolumn{4}{|c|}{ C1 } & \multicolumn{4}{|c|}{ C2 } & \multicolumn{4}{|c|}{ C3 } & \multicolumn{4}{|c|}{44} \\
\hline & 299 & 340 & & & & & & & & 86 & & & & 97 & 101 & \\
\hline & & & & & & & & & & & & & & & & \\
\hline & & & & & & & & & & & & & & & & \\
\hline & & & & & & & & & & & & & & & & \\
\hline & & & & & & & & & & & & & & & & \\
\hline & & & & & & & & & & & & & & & & \\
\hline & & & & & & & & & & & & & & & & \\
\hline & & & & & & & & & & & & & & & & \\
\hline & & & & & & & & & & & & & & & & \\
\hline & & & & & & & & & & & & & & & & \\
\hline & & 0 & & & & & & & & & & & & & & \\
\hline & & & & & & & & & & & & & & & & \\
\hline & & & & & & & & & & & & & & & & \\
\hline & & & & & & & & & & & & & & & & \\
\hline & & & & & & & & & & & & & & & & \\
\hline & 320 & 361 & & & & & & & & 40 & 60 & & 56 & 71 & 75 & 0.093 \\
\hline & & & & & & & & & & & & & & & 88 & \\
\hline & & & & & & & & & & & & & & & & \\
\hline & 70 & 211 & 0.2 & 73 & 0.10 & 0 & 229 & 0.2 & & 0.230 & 262 & 13 & .030 & .041 & .047 & 0.065 \\
\hline Hazard-20 & 68 & 309 & 0.320 & 356 & 038 & 0.076 & 104 & 0.160 & 048 & 0.166 & 0.192 & 0.243 & 0.032 & 0.045 & 0.056 & 0.071 \\
\hline
\end{tabular}

We set the FPIS and the FNIS values as: $(1,1,1,1)$ and $(0,0,0,0)$. For the next step, the distance of each alternative from FPIS and FNIS are calculated using Eqs. (18) and (19). The next step presents the similarities to an ideal solution by Eq. (20). The resulting closeness coefficients values of are reported in Table 9. 
Table 9 TrF-TOPSIS $C_{i}^{*}$ values

\begin{tabular}{llll}
\hline Hazard & $\mathrm{S}_{\mathrm{i}}^{+}$ & $\mathrm{S}_{\mathrm{i}}{ }^{-}$ & $\mathrm{C}_{\mathrm{i}}^{*}$ \\
\hline Hazard-1 & 5.811 & 1.410 & 0.195 \\
Hazard-2 & 5.526 & 1.715 & 0.237 \\
Hazard-3 & 5.541 & 1.707 & 0.235 \\
Hazard-4 & 5.772 & 1.473 & 0.203 \\
Hazard-5 & 5.364 & 1.883 & 0.260 \\
Hazard-6 & 5.711 & 1.537 & 0.212 \\
Hazard-7 & 5.508 & 1.733 & 0.239 \\
Hazard-8 & 5.547 & 1.695 & 0.234 \\
Hazard-9 & 5.520 & 1.719 & 0.237 \\
Hazard-10 & 5.492 & 1.753 & 0.242 \\
Hazard-11 & 5.532 & 1.711 & 0.236 \\
Hazard-12 & 5.944 & 1.298 & 0.179 \\
Hazard-13 & 5.437 & 1.806 & 0.249 \\
Hazard-14 & 6.027 & 1.219 & 0.168 \\
Hazard-15 & 5.819 & 1.424 & 0.197 \\
Hazard-16 & 5.819 & 1.420 & 0.196 \\
Hazard-17 & 5.752 & 1.489 & 0.206 \\
Hazard-18 & 5.768 & 1.479 & 0.204 \\
Hazard-19 & 5.854 & 1.396 & 0.193 \\
Hazard-20 & 5.999 & 1.246 & 0.172 \\
\hline
\end{tabular}

According to the TrF-TOPSIS results, the most crucial hazard is the one which has the shortest distance from the fuzzy positive ideal solution and farthest distance from the fuzzy negative ideal solution. When hazards are ordered by giving $\mathrm{Ci}^{*}$ value closest to 1 is ranked highest risk, while risks having $\mathrm{Ci}^{*}$ value farthest from 1 is ranked lowest risk.

It has been observed that amongst 20 hazards studied herein, skin exposure to fuels/oils (Hazard-5), exposure to chemicals (Hazard-13), exposure to high pressure and high temperature liquids (Hazard-10), fire (Hazard-9) and electrocution (Hazard-9) have appeared the as the hazards processing relatively high-risk ratings. Figure 3 also shows the first five ranking order of hazards with a dashed circle inside the radar chart. 


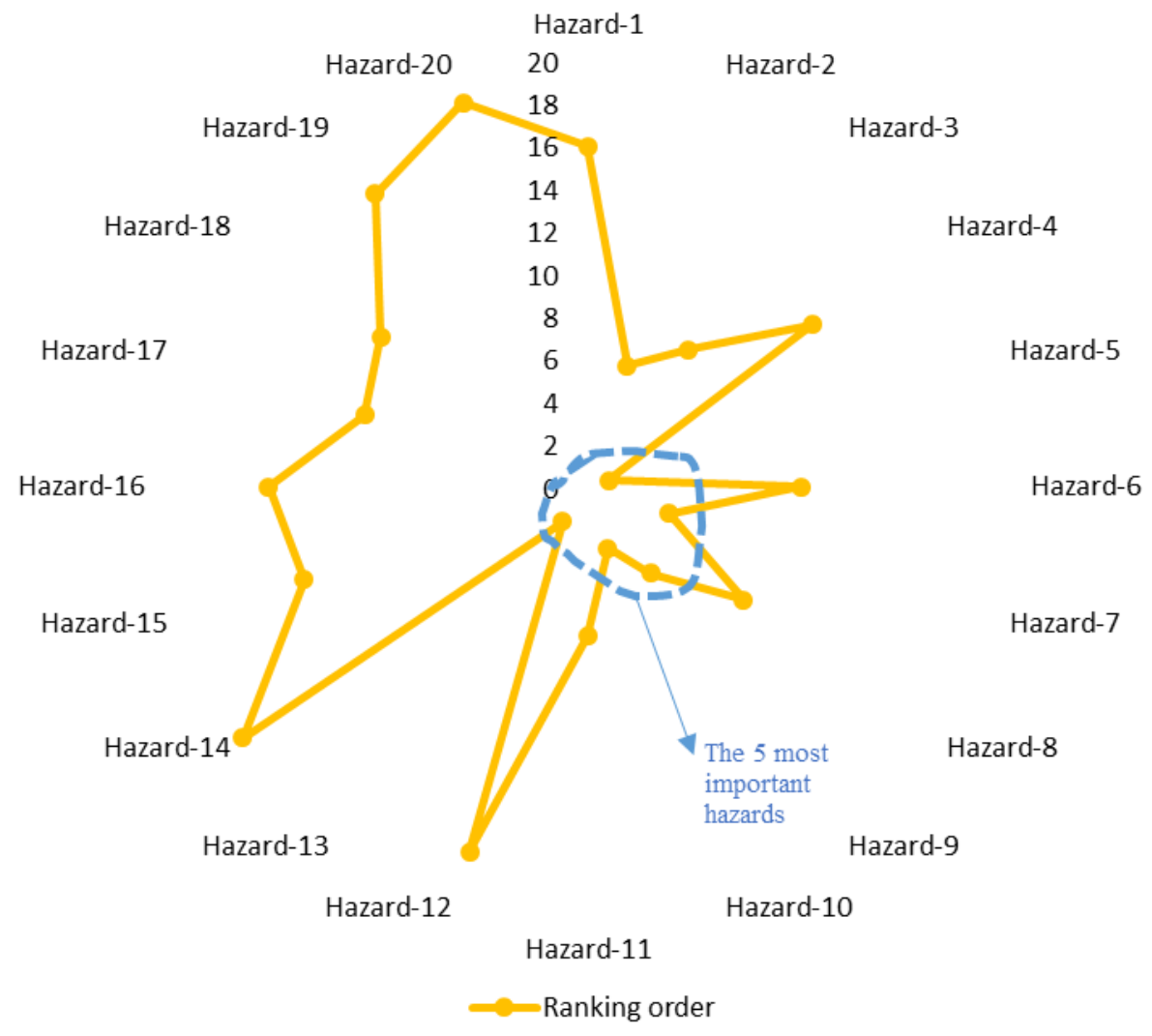

Fig. 3 Ranking order of hazards

\subsection{Control measures}

Risk assessments on ships are classified. These classifications can be listed as follows: Minor (trivial) risks, tolerable risks, controllable severe risks (moderate), major risks (substantial) and unacceptable major risks (intolerable). There is no need to take any further action than the maintenance of the controls while facing minor risks. These risks are considered acceptable. In tolerable risks, additional checks are not required as long as they cannot be implemented at a low cost (in terms of time, money and effort). To further reduce these risks, actions to be taken are given low priority. Like minor risks, the necessary arrangements must be made to maintain the controls in a complete manner. In controllable severe risks, risks could be reduced to a tolerable level and preferably to an acceptable level, but the costs of additional risk should also be taken into account. Risk mitigation measures should be applied within a defined period of time. In particular, if risk levels are associated with harmful consequences, the necessary arrangements must be made to ensure that control measures are maintained. In major risks, significant efforts should be made to reduce the risk. Risk mitigation measures should be urgently implemented within a certain period of time, and it may be necessary to consider the suspension or restriction of activities or the implementation of interim risk control measures until the completion of this procedure. It may need to allocate considerable resources to additional control measures. Especially with the level of risk is associated with extremely harmful and very harmful consequences result, all necessary arrangements to ensure sustainable control measures should be made. In this risk level, the master should inform the DPA about risk and measures. In the most important and unacceptable major risks, significant improvements in risk are required so that the risk is reduced to a tolerable or acceptable level. If the risk controls applied will not reduce the risk, the operation activity should be stopped. If it is not possible to reduce the risk, it may be necessary to keep the job prohibited. In this risk level, the master should inform the DPA about risk and measures, and also DPA should approve 
these measures or identify additional ones. Besides, in table 10 in many parts, PPE has many risk prevention features. Many PPEs are available. For example, special helmets to protect the head, special goggles to protect the eyes, headphones for protecting the hearing, protection of the respiratory organs, dressing, gloves, work shoes, hygiene-related equipment are the main ones. After giving place to these general approaches, preventive actions related to the 20 risks included in this study are presented below in Table 10. Due to the insufficiency of the studies on the risks in the ship's engine rooms, we could not compare all the risks we have encountered with the literature. However, the results of our study coincides with the results of the Eide et al. [60] which is focused on oil spill. Besides, many years ago Bloor et al. [61] studied the maritime industry-related health problems which is also matched with the results of our study. In addition, the problems used in Cicek et al. [62] study on fuel systems also support the risks that we presented in our study.

Table 10 Preventive measures for each risk

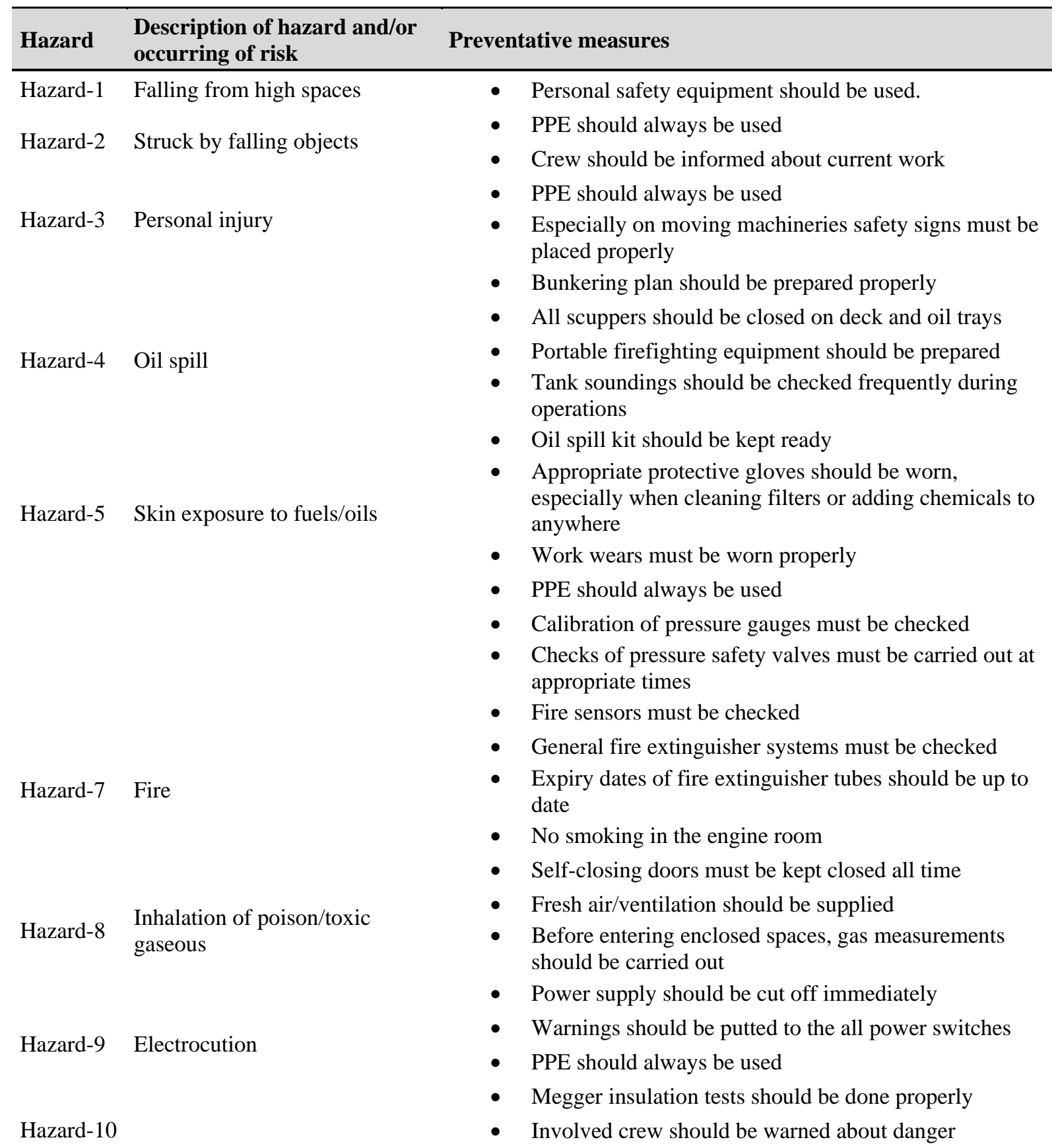


Exposure to high pressure and high temperature liquids

Hazard-11 Lifting heavy objects

Hazard-12 Excessive stress to ship structure

Hazard-13 Exposure to chemicals

Hazard-14 Interruption of power loss onboard

Hazard-15 Explosion

Hazard-16 Drop of crane or grab because of break off wire

Hazard-17 Explosion on auxiliary machinery components

Hazard-18 Loose floor plating

Hazard-19 Engine room lightning damage

Hazard-20

Involuntary explosion of carbon dioxide extinguishing system
- $\quad$ PPE should always be used

- Suitable lifting devices should be used

- Top bracing systems should be in use

- While filter cleaning or adding chemicals masks should be used

- PPE should always be used

- Emergency generator should be at automatic mode in case of power loss

- It should be ensured that the lightings used in emergency situations are operational.

- The pressure and temperature sensors must be checked, and the alarms monitored

- In the case of any high pressure the relevant equipment should be stopped

- Self-closing doors must be kept closed all time

- Never stand under hanging loads,

- Wires of the relevant device must be checked

- Warning signal of crane must be working

- Periodic maintenance and repairs of auxiliary machines should be carried out.

- $\quad$ Plating must be fixed properly

- Personal safety equipment should be used

- Intermittently interrupted lamps must be replaced immediately

- All maintenance of the diesel generator (DG) providing lighting should be carried out. Because ship provide it is electricity from DG.

- Emergency escape breathing devices (EEBD) should be present

- $\quad$ System alarm must be working properly

After the risk analysis phase, which is based on the numerical calculation of the risk, there is another phase where the risk is evaluated and controlled within certain periods. Evaluation of the risk is of course dynamic and its effect varies depending on the workplace, employer / worker and process conditions that change over time. However, it is valid for a long time unless there is a significant change and there is no reason to suspect validity. The risk assessment should be renewed according to the hazard class of the activity. In some countries (such as Turkey), there are three different hazard classes which are very hazardous, hazardous and less hazardous workplaces. These workplaces should renew their risk assessments in two-year, fouryear and six-year period, respectively. Yazdi et al. [63] presented a systematic approach to update the risk analysis results in a dynamic environment. While doing this, they benefited from two important well-known MCDM methods of DEMATEL and Best and Worst Method (BWM), as well as Bayesian Network concept.

Our proposed approach has more advantages than traditional risk analysis methods. That is, the maritime experts involved in the study are aware of the classical methods classifying risks at different levels according to their final risk scores. Opinions of these experts have been asked to differentiate the reliability of the proposed approach. With the review of these experts, it has been re-examined whether the ranking is realized in a reasonable and realistic way. In the risk categorization of the previous studies in the literature (also pointed in the literature review of this study), a categorization has been made under a certain number of risk levels (for 
example, very high risk, high risk, sustainable risk, possible risk and no action requiring risk). For this study, it has been stated by the participated experts that a categorization similar to that of five classes can be beneficial for the proposed preventive action plan in order to effectively control the emerged risks. Various risks at each level and their corresponding control action plan will enhance successful management and mitigation.

\subsection{Validation study on the results}

In this sub-section, some validation tests of the obtained results are provided. As a first validation study, we made a comparative study between the results of the current approach (integrated N-AHP \& TrF-TOPSIS approach) and another popular MCDM-based method FVIKOR [40]. In this comparative study, we used the weight values computed by N-AHP and follow the procedure of Gul [40]'s study in ranking hazards. In the computational process of FVIKOR, we benefited trapezoidal fuzzy numbers as in current approach. The defuzzification method we follow in the F-VIKOR is Circumference of Centroids method [22]. We then observe the variations in both final scores and hazard ranks. The results are shown in Fig. 4.

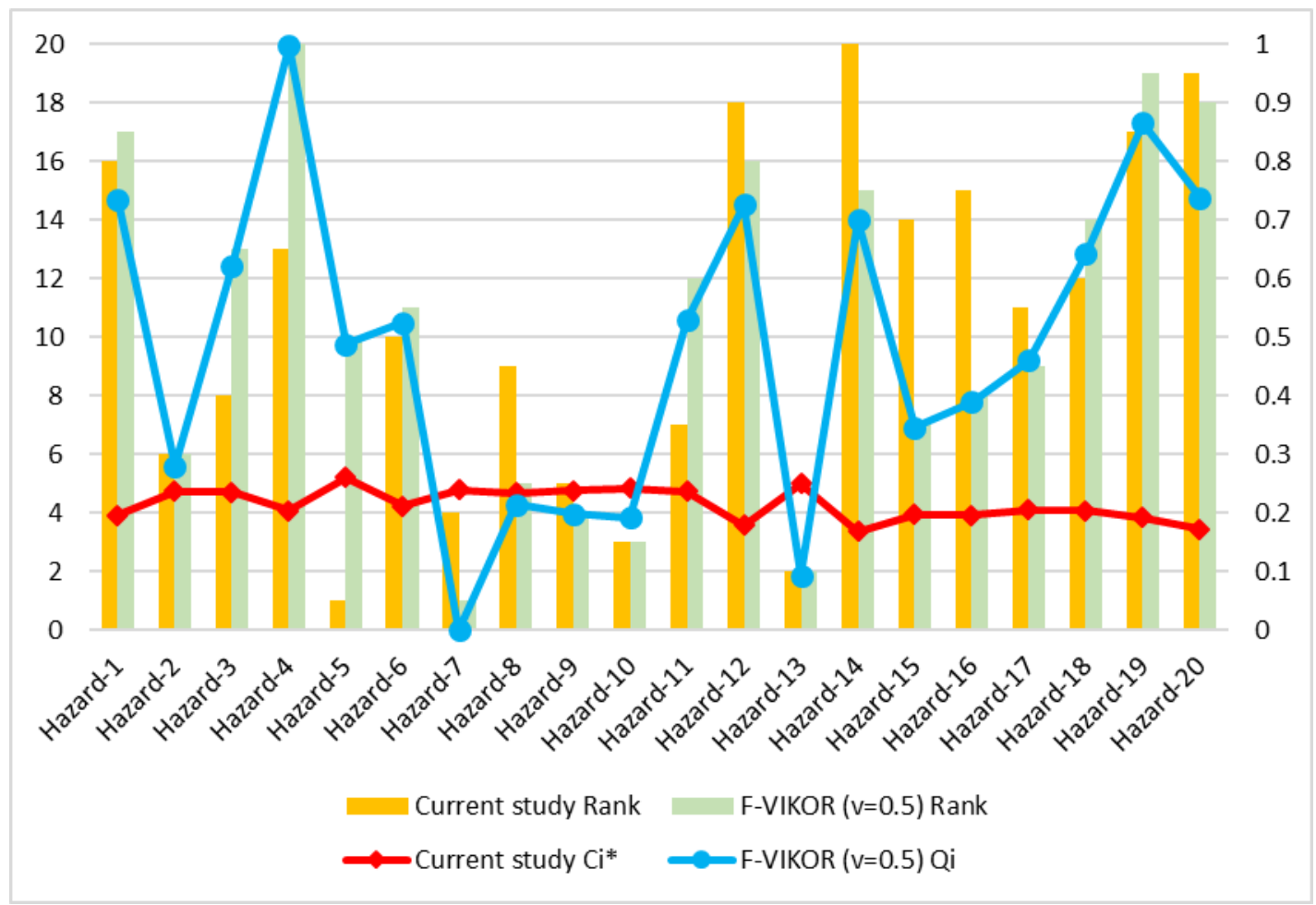

Fig. 4 First validation results: Comparison of final scores \& ranks by two approaches

According to the results obtained from Table 11, by both approaches, Hazard-13, Hazard10 and Hazard-2 have the same ranks. When compared the results in terms of final scores and ranks, we observe some variations between them. The Spearman rank correlation (RHO) between two approaches is obtained as 0.74 . That means there exists a close correlation that can be considered high between the ranking orders of two approaches. Moreover, we calculated the Pearson correlation between the final scores of both approaches. It has been obtained as 0.66. That means an intermediate opposite correlation between two approaches. Although there are some variations between both approaches, some close results are also observed. Therefore, the proposed approach is applicable for occupational risk assessment in the marine systems domain.

As a second validation study, we analyze the difference between rank of hazards in times of changing of risk parameters' weights. This is mostly called sensitivity analysis in the 
literature. Therefore, we apply four different weight vectors as given in Table 11. The rankings of hazards with respect to four different weight vectors are demonstrated in Fig. 5.

Table 11. The weight vectors designed for the sensitivity analysis

\begin{tabular}{llllll}
\hline Weight vector & Parameter & Weight value & Weight vector & Parameter & Weight value \\
\hline & C1 & 0.402 & & C1 & 0.200 \\
Weight vector-1 (WV-1) & C2 & 0.316 & Weight vector-3 (WV-3) & C2 & 0.200 \\
& C3 & 0.159 & & 0.300 \\
& C4 & 0.123 & & C4 & 0.300 \\
\hline & C1 & 0.250 & & C1 & 0.316 \\
Weight vector-2 (WV-2) & C2 & 0.250 & Weight vector-4 (WV-4) & C2 & 0.402 \\
& C3 & 0.250 & & C4 & 0.123 \\
& C4 & 0.250 & & 0.159 \\
\hline
\end{tabular}

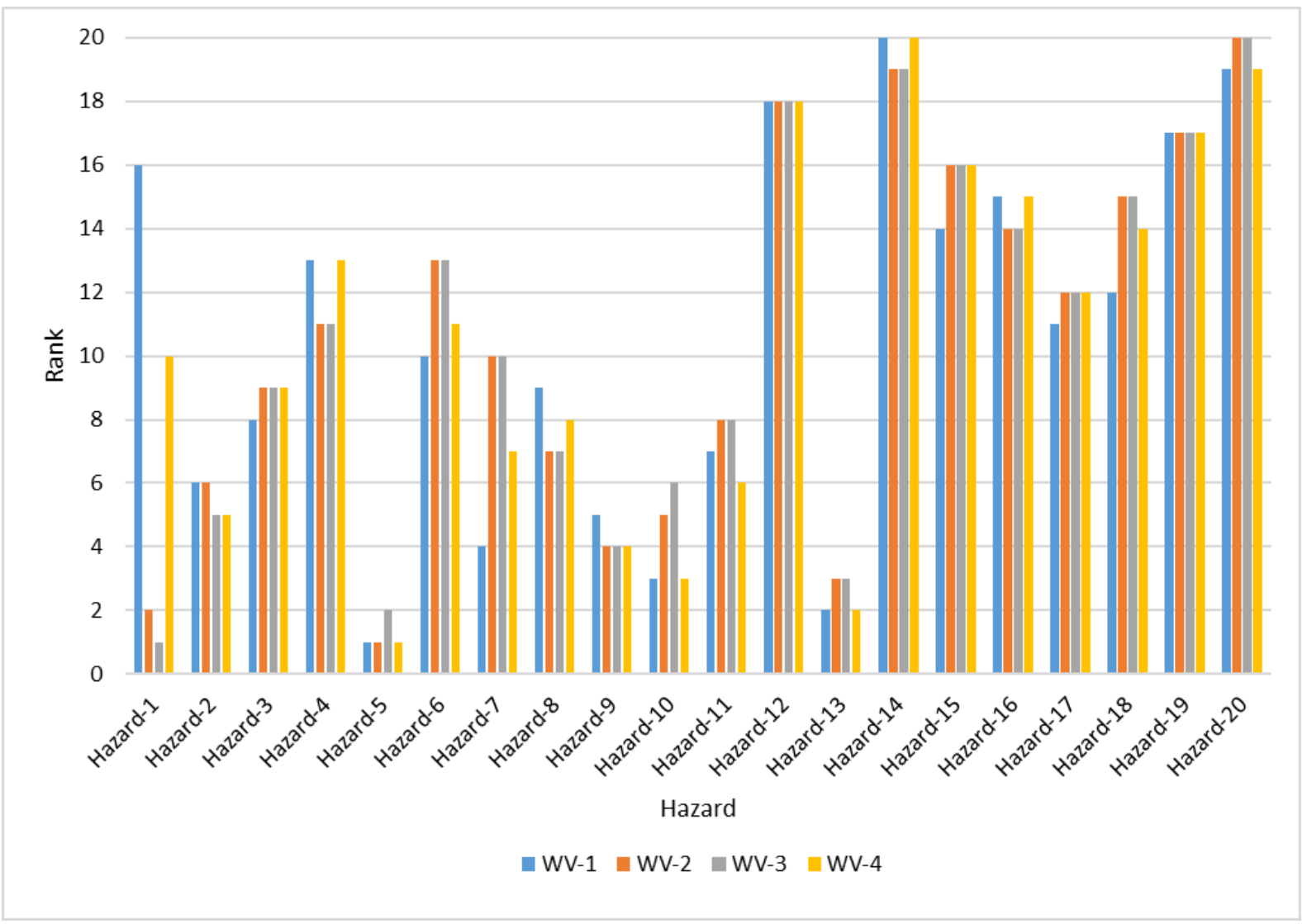

Fig. 5 Second validation results: Ranking changes in times of parameters' weights changes

It can be observed from Fig. 5 that when the weights change, it exists variations in the ranking of hazards. Therefore, our proposed approach is sensitive to risk parameters' weights. Hazard-5 is ranked as the most critical hazard according to the three weight vectors (WV-1, WV-2, WV-4). There is no change in the rankings of Hazard-12 and Hazard-19 under four weight vector combinations. They lie on the $18^{\text {th }}$ and $17^{\text {th }}$ places among the rankings. When compared to the results with the ones similar to this study from the literature, we can say that the ranking result obtained by our proposed approach is credible and applicable.

We also calculated the RHO values between weight vectors by an online calculator. The obtained results are given in Table 12. Results show that there exist high correlations between the ranking orders obtained by four different weight vectors. Since all values are close to 1 . To 
this end, we can be claimed that this proposed approach is sensitive to the changing of the weight values. It is an expected output when considered the similar attempts from the literature.

Table 12. Results of Spearman's RHO between weight vectors

\begin{tabular}{lllll}
\hline & WV-1 & WV-2 & WV-3 & WV-4 \\
\hline WV-1 & - & 0.793 & 0.766 & 0.954 \\
WV-2 & - & 0.996 & 0.927 \\
WV-3 & & - & 0.911 \\
WV-4 & & & - \\
\hline
\end{tabular}

\section{Conclusion and future agenda}

The working environments like engine rooms in the ships have faced several kinds of risks. Risk analysis in marine systems requires a great level of expert opinions and subjective judgment. Therefore, frequently encountered risks in the engine room are considered by using N-AHP \& TrF-TOPSIS methods. In maritime risk analysis, linguistic assessment of decisionmakers in evaluating risks is aided to the robustness of risk assessment tools, neutrosophic sets and fuzzy sets are used together in this study. Neutrosophic sets represent real-world problems effectively by considering all aspects of decision-making situations, (i.e. truthiness, indeterminacy, and falsity). Therefore, AHP is integrated with neutrosophic sets to assign weights of risk parameters initially. Then, the encountered risks are prioritized by TrF-TOPSIS. Finally, preventative actions for the risks have been discussed. In conclusion of the study, it is shown that skin exposure to the fuels/oils, exposure to chemicals and exposure to high pressure and temperature liquids are the most important risks through the engine room on-board. This study contributes to the literature in some aspects as follows:

(i) Neutrosophic sets integrated with AHP is adapted to maritime risk evaluation for the first time.

(ii) The second contribution of the study is regarding the proposal of a new integrated risk assessment methodology in quantifying the risk ratings. The N-AHP and TrF-TOPSIS, which are vital multi-criteria methods with neutrosophic sets and fuzzy sets, are applied integrally to the assessment of risks. By doing this, an improved approach using linguistic terms with neutrosophic set and the trapezoidal fuzzy set has been implemented. This integration successfully managed the uncertainty and vagueness of the expert teams' perceptions, simultaneous consideration of the positive and the negative ideal points, simple computation and logical concept during the subjective judgment process.

(iii) The third contribution concerns the implementation and the sector. Providing control measures can increase the level of safety control and minimize the potential environmental impacts of a ship's damage.

For future works, authors intend to further improve and adapt the methodology to evaluate navigation risks on board. From a methodological point of view, novel methods that integrate with various versions of fuzzy set theory (i.e. intuitionistic fuzzy sets, Pythagorean fuzzy sets, interval type-2 fuzzy sets, hesitant fuzzy sets, spherical fuzzy sets) can be proposed to compare the current work. 
Evaluation of frequently encountered occupational risks in

Veysi Başhan, Hakan Demirel, Muhammet Gul

ship engine rooms using neutrosophic AHP and fuzzy TOPSIS

\section{REFERENCES}

[1] "Formal Safety Assessment." http://www.imo.org/en/OurWork/Safety/SafetyTopics/Pages/FormalSafetyAssessment.aspx (accessed Dec. 09, 2019).

[2] J. Montewka, F. Goerlandt, and P. Kujala, "On a systematic perspective on risk for formal safety assessment (FSA)," Reliability Engineering \& System Safety, vol. 127, pp. 77-85, Jul. 2014, https://doi.org/10.1016/j.ress.2014.03.009

[3] P. Slovic, "Perception of risk," Science, vol. 236, no. 4799, pp. 280-285, 1987. https://doi.org/10.1126/science.3563507

[4] K. Smith, Environmental hazards: assessing risk and reducing disaster. Routledge, 2003. https://doi.org/10.4324/9780203595015

[5] P. R. Kleindorfer and G. H. Saad, "Managing disruption risks in supply chains," Production and operations management, vol. 14, no. 1, pp. 53-68, 2005. https://doi.org/10.1111/j.1937-5956.2005.tb00009.x

[6] J. F. Shroder, Biological and environmental hazards, risks, and disasters. Elsevier, 2015.

[7] V. M. Trbojevic and B. J. Carr, "Risk based methodology for safety improvements in ports," Journal of Hazardous Materials, vol. 71, no. 1-3, pp. 467-480, Jan. 2000, https://doi.org/10.1016/S03043894(99)00094-1

[8] J. Wang, “A subjective modelling tool applied to formal ship safety assessment," Ocean Engineering, vol. 27, no. 10, pp. 1019-1035, Oct. 2000, https://doi.org/10.1016/S0029-8018(99)00037-2

[9] H. P. Huntington et al., "Vessels, risks, and rules: Planning for safe shipping in Bering Strait," Marine Policy, vol. 51, pp. 119-127, Jan. 2015, https://doi.org/10.1016/j.marpol.2014.07.027

[10] S. Hu, Q. Fang, H. Xia, and Y. Xi, "Formal safety assessment based on relative risks model in ship navigation," Reliability Engineering \& System Safety, vol. 92, no. 3, pp. 369-377, Mar. 2007, https://doi.org/10.1016/j.ress.2006.04.011

[11] D. Zhang, X. Yan, J. Zhang, Z. Yang, and J. Wang, "Use of fuzzy rule-based evidential reasoning approach in the navigational risk assessment of inland waterway transportation systems," Safety Science, vol. 82, pp. 352-360, Feb. 2016, https://doi.org/10.1016/j.ssci.2015.10.004

[12] A. Mentes, H. Akyildiz, M. Yetkin, and N. Turkoglu, "A FSA based fuzzy DEMATEL approach for risk assessment of cargo ships at coasts and open seas of Turkey," Safety science, vol. 79, pp. 1-10, 2015. https://doi.org/10.1016/j.ssci.2015.05.004

[13] S. Fu, D. Zhang, J. Montewka, E. Zio, and X. Yan, “A quantitative approach for risk assessment of a ship stuck in ice in Arctic waters," Safety Science, vol. 107, pp. 145-154, Aug. 2018, https://doi.org/10.1016/j.ssci.2017.07.001

[14] H. Akyildiz and A. Mentes, "An integrated risk assessment based on uncertainty analysis for cargo vessel safety,” Safety Science, vol. 92, pp. 34-43, Feb. 2017, https://doi.org/10.1016/j.ssci.2016.09.009

[15] C. Chauvin, S. Lardjane, G. Morel, J.-P. Clostermann, and B. Langard, "Human and organisational factors in maritime accidents: Analysis of collisions at sea using the HFACS," Accident Analysis \& Prevention, vol. 59, pp. 26-37, Oct. 2013, https://doi.org/10.1016/j.aap.2013.05.006

[16] T. Kececi and O. Arslan, "SHARE technique: A novel approach to root cause analysis of ship accidents," Safety Science, vol. 96, pp. 1-21, Jul. 2017, https://doi.org/10.1016/j.ssci.2017.03.002

[17] E. Eliopoulou, A. Papanikolaou, and M. Voulgarellis, "Statistical analysis of ship accidents and review of safety level," Safety Science, vol. 85, pp. 282-292, Jun. 2016, https://doi.org/10.1016/j.ssci.2016.02.001

[18] E. Akyuz and E. Celik, "The role of human factor in maritime environment risk assessment: A practical application on Ballast Water Treatment (BWT) system in ship," Human and Ecological Risk Assessment: An International Journal, vol. 24, no. 3, pp. 653-666, Apr. 2018, https://doi.org/10.1080/10807039.2017.1396184

[19] M. Gul, E. Celik, and E. Akyuz, "A hybrid risk-based approach for maritime applications: The case of ballast tank maintenance," Human and Ecological Risk Assessment: An International Journal, vol. 23, no. 6, pp. 1389-1403, Aug. 2017, https://doi.org/10.1080/10807039.2017.1317204

[20] G. Çakıroğlu, B. Şener, and A. Balin, “Applying A Fuzzy-Ahp For The Selection Of A Suitable Tugboat Based On Propulsion System Type,” brod, vol. 69, no. 4, pp. 1-13, Dec. 2018, https://doi.org/10.21278/brod69401 
[21] H. Demirel, A. Balin, E. Celik, and F. Alarçin, “A Fuzzy Ahp And Electre Method For Selecting Stabilizing Device In Ship Industry," brod, vol. 69, no. 3, pp. 61-77, Sep. 2018, https://doi.org/10.21278/brod69304

[22] B. Akdemir and A. Beskese, "A Decision-Support Tool For Demolition Sale Of A Vessel," brod, vol. 70, no. 3, pp. 153-173, Sep. 2019, https://doi.org/10.21278/brod70309

[23] J. F. Ding, W. H. Tai, and J. F. Kuo, “A Fuzzy Evaluation Model Of Choosing A Middle Manager For An International Shipping Service Provider," brod, vol. 70, no. 1, pp. 93-107, Mar. 2019, https://doi.org/10.21278/brod70107

[24] L. KobylińSki, "Stability of ships: risk assessment due hazards created by forces of the sea," Archives of Civil and Mechanical Engineering, vol. 8, no. 1, pp. 37-45, Jan. 2008, https://doi.org/10.1016/S16449665(12)60265-9

[25] V. Başhan and H. Demirel, "Evaluation of Critical Operational Faults of Marine Diesel Generator Engines by Using DEMATEL Method," Journal of ETA Maritime Science, vol. 6, no. 2, pp. 119-128, 2018, https://doi.org/10.5505/jems.2018.24865

[26] V. Başhan and Y. Ust, "Application of fuzzy dematel method to analyse s-CO2 Brayton power systems," IFS, vol. 37, no. 6, pp. 8483-8498, Dec. 2019, https://doi.org/10.3233/JIFS-191133

[27] M. Gul and M. F. Ak, "A comparative outline for quantifying risk ratings in occupational health and safety risk assessment," Journal of Cleaner Production, vol. 196, pp. 653-664, Sep. 2018, https://doi.org/10.1016/j.jclepro.2018.06.106

[28] M. Gul and A. F. Guneri, "A fuzzy multi criteria risk assessment based on decision matrix technique: A case study for aluminum industry," Journal of Loss Prevention in the Process Industries, vol. 40, pp. 89100, Mar. 2016, https://doi.org/10.1016/j.jlp.2015.11.023

[29] M. Gul and A. F. Guneri, Use of FAHP for occupational safety risk assessment: An application in the aluminum extrusion industry In:Fuzzy Analytic Hierarchy Process. CRC Press, 2018. https://doi.org/10.1201/9781315369884-11

[30]: Nurdan Ece Oz, S. Mete, F. Serin, and M. Gul, "Risk assessment for clearing \& grading process of a natural gas pipeline project: An extended TOPSIS model with Pythagorean fuzzy sets for prioritizing hazards (Accepted, In Press),” 2018, https://doi.org/10.1080/10807039.2018.1495057

[31] S. Mahdevari, K. Shahriar, and A. Esfahanipour, "Human health and safety risks management in underground coal mines using fuzzy TOPSIS," Science of The Total Environment, vol. 488-489, pp. 8599, Aug. 2014, https://doi.org/10.1016/j.scitotenv.2014.04.076

[32] M. Yazdi, "Risk assessment based on novel intuitionistic fuzzy-hybrid-modified TOPSIS approach," Safety Science, vol. 110, pp. 438-448, Dec. 2018, https://doi.org/10.1016/j.ssci.2018.03.005

[33] M. Collan, M. Fedrizzi, and P. Luukka, "New Closeness Coefficients for Fuzzy Similarity Based Fuzzy TOPSIS: An Approach Combining Fuzzy Entropy and Multidistance," Advances in Fuzzy Systems, vol. 2015, pp. 1-12, 2015, https://doi.org/10.1155/2015/251646

[34] M. Abdel-Basset, M. Mohamed, Y. Zhou, and I. Hezam, "Multi-criteria group decision making based on neutrosophic analytic hierarchy process," Journal of Intelligent \& Fuzzy Systems, vol. 33, no. 6, pp. 40554066, Nov. 2017, https://doi.org/10.3233/JIFS-17981.

[35] F. Smarandache, "Neutrosophy and neutrosophic logic," in First International Conference on Neutrosophy, Neutrosophic Logic, Set, Probability, and Statistics University of New Mexico, Gallup, NM, 2002, vol. 87301, pp. 338-353.

[36] M. Abdel-Basset, M. Mohamed, and A. K. Sangaiah, "Neutrosophic AHP-Delphi Group decision making model based on trapezoidal neutrosophic numbers," Journal of Ambient Intelligence and Humanized Computing, vol. 9, no. 5, pp. 1427-1443, Oct. 2018, https://doi.org/10.1007/s12652-017-0548-7

[37] M. Abdel-Basset, G. Manogaran, A. Gamal, and F. Smarandache, "A hybrid approach of neutrosophic sets and DEMATEL method for developing supplier selection criteria," Design Automation for Embedded Systems, vol. 22, no. 3, pp. 257-278, Sep. 2018, https://doi.org/10.1007/s10617-018-9203-6

[38] T. L. Saaty, "A scaling method for priorities in hierarchical structures," Journal of Mathematical Psychology, vol. 15, no. 3, pp. 234-281, Jun. 1977, https://doi.org/10.1016/0022-2496(77)90033-5

[39] T. L. Saaty, The analytic hierarchy process: planning, priority setting, resource allocation. New York; London: McGraw-Hill International Book Co, 1980.

[40] T. L. Saaty, "How to make a decision: The analytic hierarchy process," European Journal of Operational Research, vol. 48, no. 1, pp. 9-26, Sep. 1990, https://doi.org/10.1016/0377-2217(90)90057-I 
Evaluation of frequently encountered occupational risks in

ship engine rooms using neutrosophic AHP and fuzzy TOPSIS

[41] T. L. Saaty, Decision making with dependence and feedback: the Analytic Network Process: the organization and prioritization of complexity. Pittsburgh: RWS Publications, 2001.

[42] D.-Y. Chang, "Applications of the extent analysis method on fuzzy AHP," European Journal of Operational Research, vol. 95, no. 3, pp. 649-655, Dec. 1996, https://doi.org/10.1016/03772217(95)00300-2

[43] C. Kahraman, B. Öztayşi, İ. Uçal Sarı, and E. Turanoğlu, "Fuzzy analytic hierarchy process with interval type-2 fuzzy sets," Knowledge-Based Systems, vol. 59, pp. 48-57, Mar. 2014, https://doi.org/10.1016/j.knosys.2014.02.001

[44] B. Oztaysi, S. C. Onar, E. Bolturk, and C. Kahraman, "Hesitant fuzzy analytic hierarchy process," in 2015 IEEE International Conference on Fuzzy Systems (FUZZ-IEEE), Istanbul, Turkey, Aug. 2015, pp. 1-7, https://doi.org/10.1109/FUZZ-IEEE.2015.7337948

[45] Z. Xu and H. Liao, "Intuitionistic Fuzzy Analytic Hierarchy Process," IEEE Transactions on Fuzzy Systems, vol. 22, no. 4, pp. 749-761, Aug. 2014, https://doi.org/10.1109/TFUZZ.2013.2272585

[46] E. Ilbahar, A. Karaşan, S. Cebi, and C. Kahraman, "A novel approach to risk assessment for occupational health and safety using Pythagorean fuzzy AHP \& fuzzy inference system,” Safety Science, vol. 103, pp. 124-136, Mar. 2018, https://doi.org/10.1016/j.ssci.2017.10.025

[47] A. Karasan, E. Ilbahar, S. Cebi, and C. Kahraman, "A new risk assessment approach: Safety and Critical Effect Analysis (SCEA) and its extension with Pythagorean fuzzy sets," Safety Science, vol. 108, pp. 173187, Oct. 2018, https://doi.org/10.1016/j.ssci.2018.04.031

[48] M. Gul, “Application of Pythagorean fuzzy AHP and VIKOR methods in occupational health and safety risk assessment: The case of a gun ad rifle barrel external surface oxidation and colouring unit (Accepted, In Press).," International Journal of Occupational Safety and Ergonomics, pp. 1-26, 2018. https://doi.org/10.1080/10803548.2018.1492251

[49] G.-H. Tzeng and J.-J. Huang, Multiple attribute decision making: methods and applications. Chapman and Hall/CRC, 2011. https://doi.org/10.1201/b11032

[50] A. F. Guneri, M. Gul, and S. Ozgurler, "A fuzzy AHP methodology for selection of risk assessment methods in occupational safety," International Journal of Risk Assessment and Management, vol. 18, no. 3/4, p. 319, 2015, https://doi.org/10.1504/IJRAM.2015.071222

[51] C.-L. Hwang and A. S. M. Masud, Multiple objective decision making-methods and applications: a stateof-the-art survey, vol. 164. Springer Science \& Business Media, 2012.

[52] E. Celik, M. Gul, A. T. Gumus, and A. F. Guneri, "A fuzzy TOPSIS approach based on trapezoidal numbers to material selection problem," Journal of Information Technology Applications \& Management, vol. 19, no. 3, pp. 19-30, 2012.

[53] C.-H. Cheng and Y. Lin, "Evaluating the best main battle tank using fuzzy decision theory with linguistic criteria evaluation," European Journal of Operational Research, vol. 142, no. 1, pp. 174-186, Oct. 2002, https://doi.org/10.1016/S0377-2217(01)00280-6

[54] C. Samantra, S. Datta, and S. S. Mahapatra, "Analysis of occupational health hazards and associated risks in fuzzy environment: a case research in an Indian underground coal mine," International Journal of Injury Control and Safety Promotion, vol. 24, no. 3, pp. 311-327, Jul. 2017, https://doi.org/10.1080/17457300.2016.1178298

[55] C.-T. Chen, "Extensions of the TOPSIS for group decision-making under fuzzy environment," Fuzzy Sets and Systems, vol. 114, no. 1, pp. 1-9, Aug. 2000, https://doi.org/10.1016/S0165-0114(97)00377-1

[56] A. C. Kutlu and M. Ekmekçioğlu, "Fuzzy failure modes and effects analysis by using fuzzy TOPSIS-based fuzzy AHP," Expert Systems with Applications, vol. 39, no. 1, pp. 61-67, Jan. 2012, https://doi.org/10.1016/j.eswa.2011.06.044

[57] S. Carpitella, A. Certa, J. Izquierdo, and C. M. La Fata, "A combined multi-criteria approach to support FMECA analyses: A real-world case,” Reliability Engineering \& System Safety, vol. 169, pp. 394-402, Jan. 2018, https://doi.org/10.1016/j.ress.2017.09.017

[58] B. Şahin and D. Yazır, "An analysis for the effects of different approaches used to determine expertise coefficients on improved fuzzy analytical hierarchy process method," Journal of the Faculty of Engineering and Architecture of Gazi University, vol. 34, no. 1, pp. 89-102, 2019.

[59] M. Yazdi, "Footprint of knowledge acquisition improvement in failure diagnosis analysis," Quality and Reliability Engineering International, vol. 35, no. 1, pp. 405-422, 2019. https://doi.org/10.1002/qre.2408

[60] M. S. Eide et al., "Prevention of oil spill from shipping by modelling of dynamic risk," Marine Pollution Bulletin, vol. 54, no. 10, pp. 1619-1633, Oct. 2007, https://doi.org/10.1016/j.marpolbul.2007.06.013 
[61] M. Bloor, M. Thomas, and T. Lane, "Health risks in the global shipping industry: An overview," Health, Risk \& Society, vol. 2, no. 3, pp. 329-340, Nov. 2000, https://doi.org/10.1080/713670163

[62] K. Cicek, H. H. Turan, Y. I. Topcu, and M. N. Searslan, "Risk-based preventive maintenance planning using Failure Mode and Effect Analysis (FMEA) for marine engine systems," in Engineering Systems Management and Its Applications (ICESMA), 2010 Second International Conference on, 2010, pp. 1-6.

[63] M. Yazdi, A. Nedjati, E. Zarei, and R. Abbassi, "A novel extension of DEMATEL approach for probabilistic safety analysis in process systems," Safety Science, vol. 121, pp. 119-136, Jan. 2020, https://doi.org/10.1016/j.ssci.2019.09.006

Submitted: $\quad$ 24.04.2019. Veysi Başhan, (*corresponding author) veysibashan@ gmail.com

Yildiz Technical University, Naval Architecture and Maritime Faculty,

Accepted: $\quad$ 24.04.2020. 34349, Besiktas, Istanbul, Turkey.

Phone: +90 212 3832936, Fax: +90 2123833021

Hakan Demirel, demirelhakan60@gmail.com

Zonguldak Bülent Ecevit University, Department of Marine Engineering

Operations, 67300, Zonguldak, Turkey.

Muhammet Gul, muhammetgul@munzur.edu.tr

Munzur University, Department of Industrial Engineering, 62000, Tunceli, Turkey. 